\title{
The Impact of Mobile Devices for Learning in Higher Education Institutions: Nigerian Universities Case Study
}

\author{
Shaibu A. Shonola and Mike S. Joy \\ Department of Computer Science, University of Warwick, CV4 7AL Coventry, United Kingdom \\ Emails: \{s.a.shonola, m.s.joy\}@warwick.ac.uk \\ Solomon S. Oyelere and Jarkko Suhonen \\ School of Computing, University of Eastern Finland, FIN-80101 Joensuu, Finland \\ Emails: \{ solomon.oyelere, jarkko.suhonen\}@cs.uef.fi
}

\begin{abstract}
Mobile devices such as smartphones and tablets are becoming increasing popular among students, setting out a new way to communicate, collaborate and learn. The use of portable devices has the capability to inspire new approaches to learning. It is therefore important to examine the students' viewpoints about the educational use of mobile technology in supporting the learning process. The purpose of this study is to determine the impact of mobile devices for learning purposes by exploring the kinds of interactions that students in Nigerian universities have with their portable gadgets. A sample of 240 higher education students participated in the study by completing the researchers' questionnaire. The results of the study indicate the students use their portable devices to exchange education-related messages and academic files with classmates, search the internet and library databases for academic materials, practice online quizzes or tests and hold discussions with classmates among others. The statistical analyses result show that there is no significant difference in the students' use of mobile devices based on gender.
\end{abstract}

Index Terms-Mobile device, handheld device, mobile learning, m-learning.

\section{INTRODUCTION}

Present developments in the field of computer and communication technologies have opened tremendous opportunities for learning. The application of computers and information communication devices is a force to be reckoned with in modern education systems. With the advent of emerging mobile technologies the need to integrate mobile devices in learning is inevitable. Mobile learning emerges as a new progression based on the use of mobile devices together with wireless communications for teaching and learning purposes [1].

Mobile learning is the delivery of educational materials and learning contents through mobile technologies [2]. Mobile technologies used in education include mobile phones, smartphones, PDAs, MP3/MP4 players, e-book readers (e.g. Kindle), netbooks, tablets (e.g. iPad, Galaxy Tab), hybrid tablet/smartphone gadgets (e.g. Galaxy Note) and specialist portable technologies used in science laboratories [3]. The use of these mobile technologies in learning improves accessibility, efficiency and quality of learning by facilitating access to education resources and services. The capability of m-learning technologies to present learning materials, not only in text, but also graphics, video and sound, and easy access via many different devices further enhances the interest of the learners [4].

Mobile learning can take place anytime anywhere, including conventional learning environments such as university classrooms, lecture theatres, libraries, and even canteens as well as learners' homes, community locations, parks, and in public transport. Students can have access to lecture notes and assignments by using mobile technological devices. It involves connectivity of mobile devices for downloading, uploading, online working via wireless networks, mobile/smart phone networks or both, and linking to university systems such as virtual learning environments (VLEs) and management information systems (MIS) [5]. It could also be in the form of mobile educational apps installed or pre-installed on certain mobile devices.

A focal point of m-learning is information sharing, which makes it possible for learners to interact with each other and share knowledge anytime. It therefore, promotes collaborative learning, extends learning beyond lecture theatres and diminishes barriers such as distance and space significantly. It can be made to support modern classroom learning tools as well as distance learning and e-learning, as a result of which lectures can be delivered in remote areas for the benefit of people across countries and continents [2].

A good implementation of mobile learning will complement and add value to existing formal learning, teaching, assessment and educational administration and management [6]. However, the impact of mobile learning in teaching and learning delivery has not been ascertained by university students in many developing countries such 
as Nigeria. This paper seeks to provide a broad assessment of the impact of mobile learning in Nigeria Higher Education Institutions and attempts to understand the effects of having lectures notes and slides on mobile devices on students learning tasks. To discover viable solutions, the paper will describe different research questions and survey activities carried out and results obtained from the study.

This paper is organised as follows. Section one is the introduction and second section is a review of related research on m-learning. It summarises existing studies on m-learning effectiveness and evaluates the recommendations made in the literature. The third part discusses the research carried out on the impacts of mlearning on students' academic performance using universities in Nigeria as a case study. It details the purpose of the research, the methodology and research questions. A brief overview of the analysis of the results of the research is presented in section four while section five gives a detailed discussion of the results gathered and statistical tests. The last part of this paper summaries the findings of the study, discusses recommendations and direction for further study.

\section{LITERATURE REVIEW}

Many research on m-learning have ascertained the acceptability and the potentials of using mobile devices in education, and the benefits of incorporating them in the classroom for collaborative learning and active student' participation. There are many studies that also discuss the effectiveness and integration of m-learning with classroom and e-learning. Reference [7] state that mobile learning is one of the developing areas in teaching and learning, and it is getting more accepted with the improved accessibility and major enhancement in the capabilities of handheld devices in terms of processing speed, screen sizes, memory capacity, storage volume and network connectivity. The authors state that the use of these modern mobile devices falls in line with planned educational goals to improve students' study retention and achievement, support segregation of learning needs, and reach out to students who would not have use their mobile phones to participate in learning. Reference [8] observes that mobile technologies offer new opportunities for students' educational activities in that they can be used across different locations and times. Therefore, learners who use mobile technologies for learning are not only far away from their lecturers and tutors, but they are also in full control by having access to information on their mobile devices, thereby giving them a certain amount of liberty, freedom and independence in their course of learning.

Reference [9] points out that the learning activity experienced by mobile owners is unique because knowledge is received and processed within the context in which the learner is located. The context is completely individual and totally different from the rigid outlay of the conventional lecture room, and science laboratories. Reference [1] show that mobile learning is most commonly used by university and higher education learners, followed by primary school students, and then adult or lifelong learners and lastly secondary school students. Their research further indicate that m-learning is mainly used by students studying in applied sciences, followed by the humanities, and then formal and social sciences and lastly natural sciences.

Many recent research projects have been focussed on the effectiveness of mobile learning and majority of them have showed positive effectiveness. An observation study by author in [10] on the effectiveness of m-learning in a university showed that students prefer podcasts to their textbooks as a learning aid. Reference [11] also found that m-learning improves retention among university students. A similar study work carried out by [12], cited by [13] showed that students who use mobile technology devices had more motivation for learning than those who do not. Furthermore, web 2.0 also has a positive effect on m-learning as [14] state: "By its very nature, not only can Web 2.0 support education but mobile Web 2.0 in particular also has the potential to blur the boundaries between formal (planned, scheduled, structured, facilitated and class based) and informal learning environments (opportunistic, non-facilitated, non-class based and entirely learner driven) and become an integral part of the process of learning and teaching."

The effectiveness of m-learning, however, faces some constraints. Reference [15] listed the constraints in three dimensions which are the human dimensions (students and instructors), the design dimension (content and technologies), and the institutional dimension (universities, colleges and schools). The human dimensions include distractions, noise, differing comfort levels, and differing visibility levels. The design dimensions include small screen size, inadequate memory, short battery life, inadequate built-in functions and the complexity of adding applications. The institutional dimensions include network speed and connectivity, content and software application limitations.

Some scholars pointed out that m-learning can neither replace nor displace classroom or other learning approaches, but only complement and add value to the existing learning methods $[2,6]$, therefore, efforts should be directed at integrating m-learning with other learning methods. The integration of m-learning with classroom and e-learning is considered as a form of blended learning strategy. Blended learning as described by [16] combines classroom instruction with e-learning or $\mathrm{m}$ learning to optimise the benefits of both face-to-face and online methods of education. Three techniques are used in integration of m-learning devices with mainstream of pedagogical instruments. An m-learning device can be a supportive tool, an instructional tool and an assessment tool. As a supportive tool, a mobile device can be used to support communication between learners and their instructors, as a file sharing mechanism, a discussion medium, as well as for information search. As an instructional tool, mobile device can be used by instructors to give learners e-books, educational content, and other learning materials. Also learners, for example, 
can execute their learning tasks on mobile devices [17]. Furthermore, an m-learning device can be used as a tool to evaluate students learning activities as an assessment tool. Above all, m-learning devices can be used to ease learning ICT modules, particularly in game programming [18].

In Nigerian Higher Education Institutions, much research have been carried out on m-learning and majority of studies are based on the implementation, prospects, possibilities and problems of m-learning in Nigeria. Reference [19] discuss the acceptance and readiness to use mobile technology by the teachers as well as the learners as a critical factor determining the success rate of mobile learning implementation. Reference [4] state the possibilities and challenges of mlearning in Nigerian universities. The challenges they raised on m-learning devices includes small screens, tiny keyboard efficient input, high price, and limited computing capability and connectivity issues. Reference [20] indicate that m-learning is the gateway to e-learning for many Nigerian students and m-learning has already started to play a vital role in e-learning in Nigeria by bringing e-learning to the learners in rural communities. The research conducted by [21] shows that learners in Nigerian universities are well prepared for m-learning as they have acquired various types of mobile devices and demonstrated a high level of operational skills for successful implementation. They concluded that government and management in the education sector should concentrate on building substantial m-learning platforms in terms of authoring, publishing and content development.

Little research has been carried out to determine the effects of having lectures notes and slides on mobile devices to help students learning and whether m-learning has real impact on students' academic performance in Nigerian universities. Consequently, any study on the effects of m-learning on students' academic performance from learners' perspectives in a developing country like Nigeria can never be underestimated. The purpose of this research work therefore, is to discuss the impacts of mobile learning on students' understanding of learning materials and subsequent academic performance on their courses, by providing justifiable answers to the following research questions.

1. Does having course materials such as slides and lecture notes on a mobile device make learning easier?

2. How does using a mobile device for learning improves students' academic performance?

3. Are university students willing to use or continue to use their mobile device for learning on a regular basis?

\section{METHODOLOGY}

This study employed a quantitative research method using a random sample population of students from two Universities in South-West Nigeria. The data collection method involved delivering a set of questionnaires to 250 randomly selected students. The questionnaire comprised of single and multiple choice questions divided into two sections. The first section was on demography to collect personal information about the respondents. Questions in section two were concerned with the mobile devices used by the respondents and the type of activities they were being used for. It also gathered data on m-learning awareness, educational activities, and if m-learning improves students' learning skills and academic performance.

The questionnaires were given out to the students during the first semester of 2014/2015 academic year after ethical consent was sought and obtained for the survey through the authors' university while the respondents were assured anonymity. 240 questionnaires were returned to the researchers, a $96 \%$ response rate which is an expected rate for such surveys. The data collected was analysed and presented using frequency distributions, pie charts, histograms and statistical tests. Most of the participants were undergraduate students, studying for a Bachelor degree, with a small $28 \%$ studying for a Masters' degree as shown in Fig. 1. Table 1 also shows the demographic information about the participants.

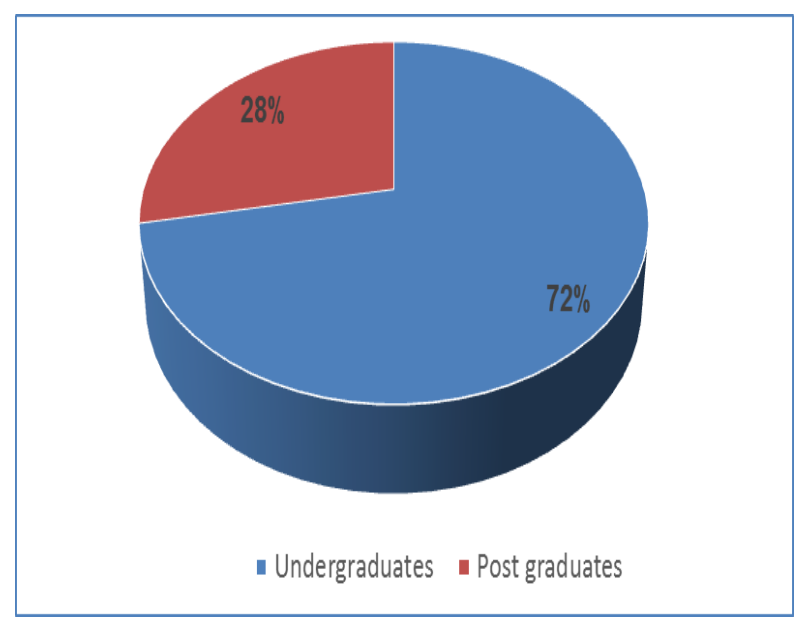

Fig.1. Percentage of participants' courses

Table 1. Participants' Demographic Information

\begin{tabular}{|c|c|c|c|c|}
\hline Gender/Age & $16-19$ & $20-23$ & 24 and over & Total \\
\hline Female & 35 & 44 & 23 & 102 \\
\hline Male & 43 & 59 & 36 & 138 \\
\hline Total & 78 & 103 & 59 & 240 \\
\hline
\end{tabular}




\section{RESULTS AND FINDINGS}

The empirical findings of this study are organised into three sections in order to provide answers to the research questions as analysed below:

A. Research Question 1: Does having course materials such as lecture slides and notes on mobile device makes learning easier?

This first single choice question of the survey is to determine if lecture slides and notes on m-learning device makes learning easier based on students' opinion or experience. An overwhelming $88.2 \%$ of the female and $83.3 \%$ of the male participants agreed or strongly agreed that having slides and materials makes learning easier as shown in fig. 2 below.

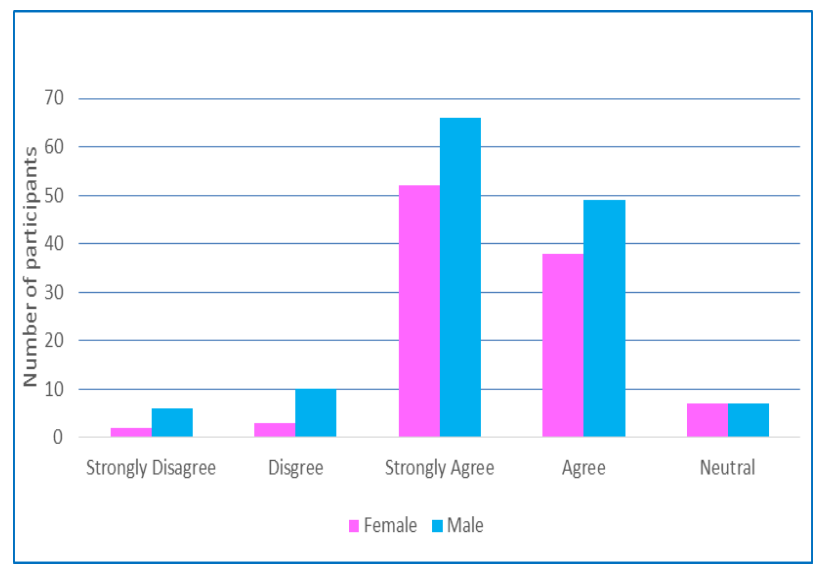

Fig.2. Having lecture slides and notes on mobile devices

A very low percentage of the survey $(4.9 \%$ and $11.6 \%$ of female and male participants respectively) disagreed or strongly disagreed that having learning materials on portable devices makes learning easier while $6.9 \%$ of the male and $5.1 \%$ of the female are neutral on this statement.

B. Research Question 2: How does using a mobile device for learning improves students' academic performance?

The findings from this research question indicate that majority of the participants $(92.6 \%)$ are of the view that their performance has improved or could improve by using their portable device for learning purposes. The result shows that eight out of ten students indicate their learning and grades improves significantly in courses in which they engage in m-learning activities such as practising online exercises.

In order to determine which m-learning activities students engaged in their studies that eventually led to improved performance, some online activities were itemised in the questionnaire having multiple choice options to pick from them, as shown in table 2 below.

The result of the analysis of the itemised online activities is shown in fig. 3 below, that studying and researching are the most educational activities that students agreed or strongly agreed to engage with when using mobile devices for learning, which is followed by communicating with fellow students and practising online exercises that are related to their courses. Downloading, storing and sharing educational materials and information are also agreed or strongly agreed activities being performed by the student on mobile learning devices.

Table 2. M-learning activities

\begin{tabular}{cl}
\hline \multicolumn{1}{l}{ Item } \\
No & Item Description \\
\hline 1 & Taking notes in the class \\
2 & Studying and Researching \\
3 & Downloading and storing learning material \\
4 & Sharing materials \& information \\
5 & Practising online exercises \\
6 & Communicating with fellow students \\
7 & Receiving grades and feedback \\
\hline
\end{tabular}

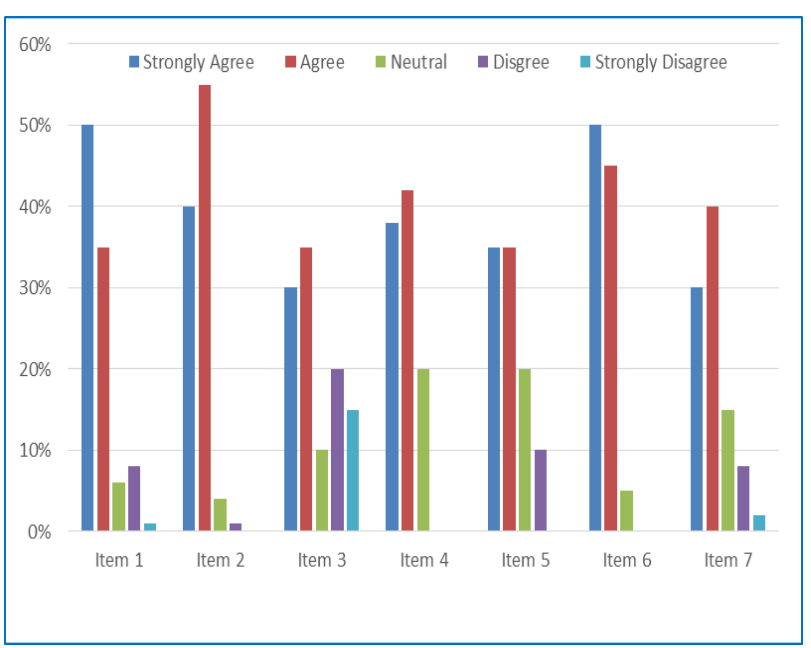

Fig.3. Participants view on m-learning activities. Descriptions of item 1 -7 are given in table 2 above.

Engaging in all or most of the m-learning activities above with classroom learning is likely to improve students' academic performance in their courses as revealed by this research study and supported by previous research which are cited in the discussion section below.

\section{Research Question 3: Are university students willing to use or continue to use their mobile device for learning on a regular basis?}

This single choice closed question of the survey determines the sustainability of m-learning by asking if the students are using their device for learning on regular basis and will continue to do so in future. A large proportion of the participants' population (88\%) indicated "Yes" while $9 \%$ and $3 \%$ of the sample stated "Not sure" and "No" respectively as shown in fig. 4 below. 


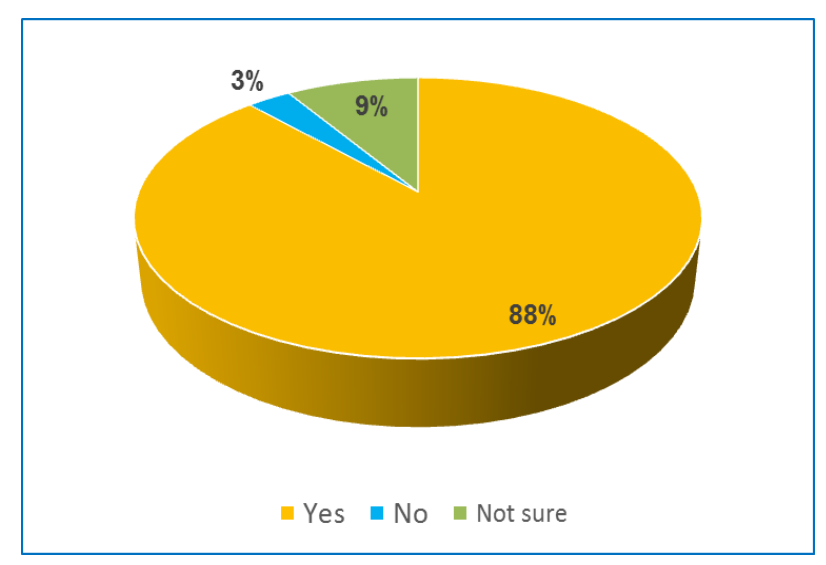

Fig.4. M-learning usage

\section{DISCUSSIONS}

The perceptions of the learners remain very important in the adoption, implementation and use of any mobile innovation in education system. Thus, the primary purpose of this study is to investigate mobile device use in tertiary education based on students' perceptions. In particular, we are very interested to study how Nigerian students use mobile technology and if the technology can help improve their academic performance. Since almost every student has access to smartphone for personal use, adapting the device for learning is not a bad idea through social media-based learning platform [10].

The finding from research question 1, fig. 2, shows that having course materials such as lecture slides and notes on a mobile device makes learning easier for the students, as they can use their device to study at anytime, anywhere. This enables the students to engage in learning activities even when they are outside their classrooms and improves flexibility for self-study. By making academic courses more accessible through mobile devices, the amount of information retained from the personal study is often greater, which results in increased information retention and grade performance. This outcome is consistent with the study conducted by [22] in which $74 \%$ of the participants indicated that their mobile devices gave them easy access to learning resources and online repository. It is also supported by [23] who note that mobile phones are widely used by students to access and support learning. It is therefore, appropriate to conclude that mobile technologies offer extensive access opportunities for learners, particularly in researching and learning.

Taking gender variable into account, the findings of this research question indicate that more males agreed or strongly agreed that having lecture slides and notes on mobile device makes learning easier. This result was further analysed using the chi-square statistical test for dependency based on gender demographic information. The chi-square statistic was calculated to be 3.4998 , the $\mathrm{P}$-value is 0.477909 , at the confidence interval of 0.05 as shown in table 3 below. This statistical test confirms that there is no gender difference on having course materials on mobile devices and that both genders have the same positive view on having learning materials on mobile gadgets.

Table 3. Students' perception on having course materials on mobile device

\begin{tabular}{|l|l|l|l|l|l|l|}
\hline \multicolumn{7}{|c|}{ Does having course materials such as lecture slides and notes on mobile device } \\
makes learning easier?
\end{tabular}

It is clear from the result of the research question two that using mobile device for learning have significant impacts in improving students' grade and performance in their study since the device is augmenting classroom learning. The result is consistent with the study of [1] which indicates $86 \%$ of studies reported favourable outcomes as a result of using m-learning while only $4 \%$ and $1 \%$ respectively reported neutral and negative experiences and 9\% are non-applicable. Another interesting research is finding out how the m-learning activities listed in table 2 help students to improve on their performances. The first learning activity is using smartphones and tablets to take notes in classes, which around $85 \%$ of the participants agreed or strongly agreed on. This outcome is supported by the study of [5] that students consider that writing with a stylus pen is more intuitive and they are therefore inclined to use tablets for note- takings in classes. In addition to note-taking, many learners also use their mobile devices for recording of lectures and class materials [13]. Other learning activities for which mobile devices are used are studying, researching and downloading learning materials as claimed by $65 \%-95 \%$ of the participants. This result is in line with the work of many academic researchers. Reference [4] argued that students can conduct research, download and store text-based materials and read resources using their mobile devices. Reference [5] listed the educational activities which students use m-learning devices for, and these include access to documents or document libraries, participation in lessons and tutorials, and reading asynchronous postings.

Practising online exercises and self-assessment questions are other learning activities that students can use their portable devices for, which $70 \%$ for the agreed or strongly agreed with. Reference [24] indicated that as a result of m-learning, students continue to learn, review and stay reminded of assignments, upcoming tests and quizzes, and any other activities occurring in the classroom once they leave school for the day. Communicating with fellow students and getting feedback on assessments and grade are some of the activities that mobile devices are also used, which are widely agreed upon by $70 \%$ to $95 \%$ of the students as shown in figure 3 and many researchers are in support of 
these views. Smartphones can provide students with collaborative learning opportunities through text messages and chatting [7]. Faculty members can utilise mobile technology to deliver content to students and provide them with timely feedback [25]. Communication is a lot easier with teachers and classmates making learning encouraging as students can chat with their colleagues to clarify doubts [22]. Reference [26] also indicated that students used smartphones for secondary reasons, including data storage and to obtain information about attended lectures, test dates, homework assignments, grades and schedules. Thus, using mobile devices can allow students to manage their personal information.

Statistical validation was carried out using a nonparametric Mann-Whitney U Test on the m-learning activities that students were engaged with, that boost their academic performance, based on gender demography as shown in table 4 and table 5 below.

Table 4. Ranking of mobile learning device activities

\begin{tabular}{|c|c|c|c|}
\hline Gender & Participants & mean of ranks & sum of ranks \\
\hline Female & 102 & 5.43 & 38 \\
\hline Male & 138 & 9.75 & 67 \\
\hline Total & 240 & 7.5 & 105 \\
\hline
\end{tabular}

Table 5. Mann-Whitney Test

\begin{tabular}{|c|c|}
\hline Test & M-learning activities on students' academic performance \\
\hline U Mann - Whitney & 10 (critical value of $\mathrm{u}$ is 8) \\
\hline $\mathrm{Z}$ & -1.7889 \\
\hline p-value (2-tailed) & 0.05 \\
\hline
\end{tabular}

According to Table 5, there is no significant difference between the rank of the female and male students views on m-learning activities on their academic performance. This implies that students irrespective of their gender are engaged in the same or similar activities when using their mobile devices for learning purposes. This outcome is expected as students either male or female are interested in improving their academic performance and are willing to engage in various m-learning activities to achieve their aims.

Fig. 4 illustrates the students' consideration on willing to use or continue to use their mobile device for learning on a regular basis in relation to research question 3 . Almost nine out of ten participants indicate that they will continue to use their portable device not only for games or personal events but also for academic activities. This result is in line with study carried out by [27] in which $80 \%$ to $90 \%$ of the participants responded with 'strongly agree' or 'agree' option on their willingness to have mobile technology augmented into their course materials.

In uniformity with other research questions, the result was further analysed using the chi-square statistical test for dependency based on the demographic information in order to determine if gender produces significant difference in students' willingness to continue using their mobile device for learning. The chi-square statistic was calculated to be 0.022 , the P-value is 0.989039 , at the confidence interval of 0.05 as shown in table 6 below. The result shows that there is no gender difference on participants' willingness to continue using their mobile devices for learning purposes. This statistical test confirms that gender does not affect university students' use or continue use of mobile device for learning on a regular basis.

Table 6. Participants willingness to continue using their devices for mlearning

\begin{tabular}{|l|l|l|l|l|}
\hline \multicolumn{5}{|c|}{ Are students willing to continue using m-learning regularly? } \\
\hline & Yes & No & Not Sure & $\begin{array}{l}\text { Row } \\
\text { Totals }\end{array}$ \\
\hline \multirow{2}{*}{ Female } & $\begin{array}{l}94(93.63) \\
{[0.00]}\end{array}$ & $\begin{array}{l}3(3.09) \\
{[0.00]}\end{array}$ & $\begin{array}{l}9(9.28) \\
{[0.01]}\end{array}$ & 106 \\
\hline \multirow{2}{*}{ Male } & $118(118.37)$ & $4(3.91)$ & $12(11.72)$ & 134 \\
& {$[0.00]$} & {$[0.00]$} & {$[0.01]$} & 21 \\
\hline Col.Total & 212 & 7 & 240 \\
\hline
\end{tabular}

While the participants were advised to answer the questionnaires from their personal experience which they have previously had when using their mobile for learning, some students might have answered the questionnaires partly on their theoretical knowledge rather than their practical individual experience. Therefore, there may be some form of subjectivity in the answers given by the participants. Nevertheless, the results obtained from this study appear accurate and are consistent with related studies conducted in the field of m-learning in other parts of the world.

\section{CONCLUSION AND FUTURE WORK}

This article discusses the impact of mobile devices for learning in Higher Education Institutions in Nigeria, which is expanding the possibilities of open and distance learning education. The analysis of students' perceptions on m-learning points to the fact that mobile learning is widely embraced by the students and they are also willing to embrace the use of their mobile devices for learning purposes not only to augment classroom lectures but also to achieve the globalisation objective [5]. Students' interest and expertise are of great potential for m-learning if integrated into their learning curriculum [28]. Therefore mobile phones can provide students with a means of individualised learning [29] through searching the internet and library for education-related materials, and there is no need for lab or library PCs to be free before they can engage in quality study and research activities. This ubiquitous learning is made possible because students are keen to use all available sources of m-learning approaches through palmtops, tablets, smartphones and PDAs to access knowledge and information anytime and anywhere. In conclusion, university students in Nigeria are using their smartphones and tablets to support learning inside and outside the classroom. There is no doubt that patronage in mobile learning is going to increase as communication 
technology advances [30], particularly in Nigeria which is ranked among the largest mobile markets in Africa.

The article ends with recommendations and future research work. First, this study should be extended to more university students in Nigeria in order to better understand mobile device usage in education. Second, more research should be carried out regarding tablets and smartphone usage in order to make available in-depth information to academics and non-academics, so they can provide quality education to students. Third, since mobile learning is spreading rapidly and likely to become one of the most efficient ways of delivering higher education instruction in the future, it is necessary to look into ways to adapt the device easily for learning and other curricula activities. It is also important to examine the implication of adopting mobile learning in terms of privacy and security.

\section{REFERENCES}

[1] W.H. Wu, Y.C.J. Wu, C.Y. Chen, H.Y. Kao, C.H. Lin and S.H. Huang, "Review of trend from mobile learning studies: a meta-analysis", Computers \& Education, vol. 59 , pp. 817-827, 2012.

[2] J. Sitthiworachart and M.S. Joy, "Is mobile learning a substitute for electronic learning?" Proceedings of the International Conference on e-Learning, IADIS Amsterdam, 2008.

[3] A. Maiti and B. Tripathy, "Different platforms for remote laboratories in mobile devices", International Journal of Modern Education and Computer Science (IJMECS), vol.4, no. 5, pp.38, 2012

[4] A.U. Okeke and T. A. Umoru, "M-learning in Nigerian universities: challenges and possibilities", Global Awareness Society International 21st Annual Conference, New York City, 2012

[5] M. Hashemi, M. Azizinezhad, V. Najafi, and A.J. Nesari, "What is mobile learning? challenges and capabilities", Procedia - Social and Behavioural Sciences, vol.30, pp. $2477-2481,2011$.

[6] N.C. Ozuorcun and F. Tabak, "Is m-learning versus elearning or are they supporting each other", Procedia Social and Science Behaviour, vol.46, pp. 294-305, 2012.

[7] A. Kukulska-Hulme, M. Sharples, M. Milrad, I. ArnedilloSánchez, and G. Vavoula, "Innovation in mobile learning: a European perspective", International Journal of Mobile and Blended Learning, vol.1, no.1, pp.13-35, 2009.

[8] L. Uden, "Activity theory for designing mobile learning", Journal of Mobile Learning and Organisation, vol.1, no.1, pp. 81-102, 2007.

[9] K. Walker, "Introduction: mapping the landscape of mobile learning", In M. Sharples (Ed.), Big Issue in mobile learning: a report of a new workshop by the kaleidoscope network of excellence mobile learning initiative (pp. 5-6), UK. [Learning Science and Research Institution: University of Nottingham, 2007]

[10] S.S. Oyelere, V. Paliktzoglou and J. Suhonen, "M-learning in Nigerian higher education: an experimental study with Edmodo", International Journal of Social Media and Interactive Learning Environments, vol. 4, no. 1, pp.43-62, 2016.

[11] F.N. Al-Fahad, "Students' attitudes and perceptions towards the effectiveness of mobile learning in King Saud university, Saudi Arabia", The Turkish Online Journal of Educational Technology, vol.8, no.2, pp.111-119, 2009.
[12] Y. Levy, M.M. Ramimand and A.R. Hackney, "Assessing ethical severity of e-learning systems security attacks", Journal of Computer Information Systems, vol.53, no.3, pp.75-84, 2013.

[13] Z. Taleb and A. Sohrabi, "Learning on the move: the use of mobile technology to support learning for university students", Procedia-Social and Behavioral Sciences, vol.69, pp.1102-1109, 2012.

[14] M. Terras and J. Ramsay, "The five central psychological challenges facing effective mobile learning", British Journal of Educational Technology, vol.43, no.5, pp.820 832, 2012.

[15] D.Vogel, D. Kennedy and R.C.W. Kwok, "Does using mobile device applications lead to learning?" Journal of Interactive Learning Research, vol. 20, pp.469-485, 2009.

[16] U. Kose, "A blended learning model supported with web 2.0 technologies", Procedia Social and Behavioral Sciences, vol.2, pp.2794-2802, 2010.

[17] D. Ktoridou and N. Eteokleous, "Adaptive m-learning: technological and pedagogical aspects to be considered in Cyprus tertiary education", Recent Research Developments in Learning Technologies, pp. 1-8, 2005.

[18] S.S. Oyelere, J. Suhonen and E. Sutinen, "M-learning: a new paradigm of learning ICT in Nigeria", International Journal of Interactive Mobile Technologies (iJIM), vol. 10 no. 1, pp. 35-44, 2016.

[19] S.A Shonola and M.S. Joy, "Barriers to m-learning in higher education institutions in Nigeria" A Proceeding of International Conference of Education, Research and Innovation (ICERI2014), Seville, Spain, pp. 3324 - 32, 2014

[20] O. K. Boyinbode and R. O. Akinyede, "Mobile learning: an application of mobile and wireless technologies in Nigerian learning system", International Journal of Computer Science and Network Security, vol.8, no.11, 2008.

[21] M.I. Rafiu, S.A. Kayode, and T.O. Rapheal, "Implementing mobile elearning in Nigeria tertiary educational system - a feasibility study", International Journal of Science and Advanced Technology, vol.1, no.1, pp.7, 2011.

[22] S. M. Jacob and B. Issac, "Mobile learning in transforming higher education", IMCL Conference, Amman, Jordan, April 18 -20, 2007.

[23] R.A. Aderinoye, K.O. Ojokheta and A.A. Olojede, "Integrating mobile learning into nomadic education programmes in Nigeria: issues and perspectives", International Review of Research in Open and Distance Learning, vol.8, no.2, pp.44-52, 2007.

[24] J. Kadirire, J, "Instant messaging for creating interactive and collaborative m-learning environments", International Review of Research in Open and Distance Learning, vol.8, no.2, pp.50-64, 2007.

[25] S.A. Shonola and M.S. Joy, "Mobile learning security issues from lecturers' perspectives (Nigerian universities case study)", 6th International Conference on Education and New Learning Technologies, Barcelona, Spain. pp. 7081-88, 2014.

[26] J. Trinder, "Mobile technologies and systems," in A. Kukulska-Hulme and J. Traxler (Eds) Mobile learning: a handbook for educators and trainers, Taylor \& Francis, 2005.

[27] H. R. Abachi and G. Muhammad, "The impact of mlearning technology on students and educators," Computers in Human Behavior, vol.30, pp.491-496, 2014. 
[28] C. Dale and G. Povey, "An evaluation of learnergenerated content and podcasting," Journal of Hospitality, Leisure, Sport and Tourism Education, 2009.

[29] S. H. Kim, C. Mims and K.P. Holmes, "An introduction to current trends and benefits of mobile wireless technology use in higher education", AACE Journal, vol.14, no.1, pp.77-100, 2006

[30] K. B. Moses, "Mobile communication evolution", International Journal of Modern Education and Computer Science, (IJMECS), vol.6, no.1, pp.25, 2014.

\section{Authors' Profiles}

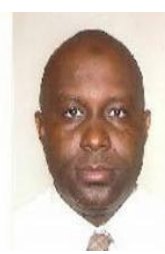

Shaibu Adekunle Shonola is a $\mathrm{PhD}$ student and researcher at the Computer Science Department, University of Warwick, UK. His research interests include mobile computing and security, educational technology, computer science education and adaptive systems.

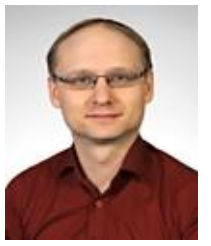

Jarkko Suhonen holds a senior researcher position at the School of Computing, University of Eastern Finland. His main research interests are related to the design, development and evaluation of blended and open learning solutions and technologies. He has published more than 50 peer reviewed scientific articles.

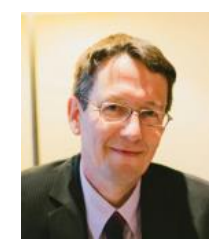

Mike .S. Joy is an associate professor at the Computer Science Department, University of Warwick, UK. His research interests are in the fields of educational technology, computer science education, agent-based Systems and internet software.

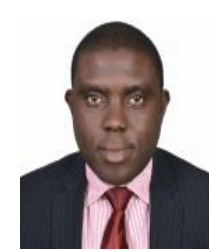

Solomon Sunday Oyelere holds early stage researcher and $\mathrm{PhD}$ position at School of Computing, University of Eastern Finland. His research interests are in the fields of mobile computing, computer science education and mobile robotics. He has several years of experience as a Lecturer in Computer Science at Modibbo Adama University of Technology, YolaNigeria and Dorben Polytechnic Abuja-Nigeria.

How to cite this paper: Shaibu A. Shonola, Mike S. Joy, Solomon S. Oyelere, Jarkko Suhonen,"The Impact of Mobile Devices for Learning in Higher Education Institutions: Nigerian Universities Case Study", International Journal of Modern Education and Computer Science(IJMECS), Vol.8, No.8, pp.43-50, 2016.DOI: 10.5815/ijmecs.2016.08.06 